\title{
Single Mode High Refractive Index Optical Fibres
}

\author{
D. Dorosz ${ }^{a}$, K. BarczaK ${ }^{b}$, T. Pustelny ${ }^{b, *}$ And J. Dorosz ${ }^{a}$ \\ ${ }^{a}$ Department of Optical Radiation, Białystok Technical University \\ Wiejska 45, 15-950 Białystok, Poland \\ ${ }^{b}$ Institute of Physics, Silesian University of Technology \\ Krzywoustego 2, 44-100 Gliwice, Poland
}

\begin{abstract}
The present paper is focussed on the search of technology of new kinds of optical fibers characterised by good magnetooptical properties. The elaborated optical fibres are to apply in optical sensors of electric current and the magnetic field. In result of these researches and analyses a new optical fibre was put forward. Such optical fibers were designed, produced and subjected to extensive tests. This paper presents the results of investigations that were carried out as well as the parameters of the tested structures.
\end{abstract}

PACS numbers: 42.81.Pa, 42.81.-i, 42.81.Qb

\section{The technology of new type of optical fibers with good magnetooptic properties}

Chemical syntheses of optical glasses were realised in an electric furnace at a temperature of $1550^{\circ} \mathrm{C}$ in argon atmosphere. As basic technological substrates raw oxide materials were used $(4 \mathrm{~N})$. The melting processes of glasses were realised in platinum crucibles, during $1.5 \mathrm{~h}$, pouring melted glass into a warmed mould. Such produced glasses were unstressed at a temperature of $400-450^{\circ}$, depending on their chemical composition. As a glassy matrix for projecting fibres a silica glass was used modified by the following oxides: $\mathrm{PbO}, \mathrm{Al}_{2} \mathrm{O}_{3}, \mathrm{~B}_{2} \mathrm{O}_{3}, \mathrm{Na}_{2} \mathrm{O}, \mathrm{K}_{2} \mathrm{O}$ [1-4]. The glass forming regimes at respective components of the investigated structures comprised: $\mathrm{SiO}_{2}$ (55-70 mol\%), $\mathrm{PbO}$ (8-20 mol\%), $\mathrm{Al}_{2} \mathrm{O}_{3}$ (6-10 mol\%), $\mathrm{B}_{2} \mathrm{O}_{3}$ (1-5 mol\%), $\mathrm{Na}_{2} \mathrm{O}(5-8 \mathrm{~mol} \%), \mathrm{K}_{2} \mathrm{O}(4-7 \mathrm{~mol} \%)$.

The amorphism of the glasses was tested by X-ray diffraction. The thermal properties of elaborated optical glasses were tested by means of the thermal differential method (differential scanning calorimetry, DSC) (making use of the Setaram Labsys Model). Samples of the obtained glasses with a mass of $50 \mathrm{mg}$

*corresponding author; e-mail: tadeusz.pustelny@polsl.pl 
were heated in platinum crucibles at a rate of $10^{\circ} \mathrm{C} / \mathrm{min}$ rate in argon atmosphere from room temperature to $1100^{\circ} \mathrm{C}$. The capacity of the glasses to crystallisation was determined by means of the value of crystallisation temperatures. Measurements of the thermal expansion coefficient were carried out on samples with the dimensions $5 \times 5 \times 20 \mathrm{~mm}^{3}$, heated from room temperature to $600^{\circ} \mathrm{C}$ at a rate of $10^{\circ} \mathrm{C} / \mathrm{min}$. The densities of the glasses were determined by hydrostatic weighing. The microhardnesses of the glasses were obtained by means of the Vickers method measuring the parameters of the imprint of the diamond pyramid by loading it for $5 \mathrm{~s}$ by $100 \mathrm{~g}$ loading in a tested sample. In polished glass samples with the dimensions $10 \times 10 \times 2 \mathrm{~mm}^{3}$ the transmission of light was tested in the spectral range $0.2-1.1 \mu \mathrm{m}$ by means of a monohromator of the OL-750 type with a detector of the type Silicon HSD-300. The refractive indices of the tested glass samples were obtained using a refractometer of the type Metricon Model 2010/M.

Single mode optical fibres were produced applying the crucible method. In the core and the cladding of the produced optical fibres there were applied glasses with refractive indices $n_{\mathrm{r}}=1.6195 \mathrm{i} n_{\mathrm{p}}=1.6190$, respectively. The composition of the glass of the cladding is a modified composition of the core glass, changing the percentage of $\mathrm{PbO} / \mathrm{Al}_{2} \mathrm{O}_{3}$ in order to reduce the value of its refractive index. Thus the core and cladding glasses possessed similar technological properties, such as viscosity and the thermal expansion coefficient, which guarantees minimum internal stresses in the elaborated fibres.

Light attenuations into optical fibres were determined for the wavelength $632.8 \mathrm{~nm}$. The mechanical endurance of optical fibres was characterised by determining the Weibull distribution (for a series of 50 raptures) and at a minimal bending diameter of the fibre $[3,5,6]$.

\section{Results of optical fibre investigations}

The basic properties of the used glass of the type: $\mathrm{SiO}_{2}-\mathrm{PbO}-\mathrm{Al}_{2} \mathrm{O}_{3}-\mathrm{B}_{2} \mathrm{O}_{3}-$ $\mathrm{Na}_{2} \mathrm{O}-\mathrm{K}_{2} \mathrm{O}$ are presented in Table I.

TABLE I

Properties of the glass.

\begin{tabular}{l|c}
\hline \hline \multicolumn{1}{c|}{ Parameters } & Range \\
\hline density $\left[\mathrm{g} / \mathrm{cm}^{3}\right]$ & $3.78-3.8$ \\
microhardness $[\mathrm{GPa}]$ & $8.9-9.2$ \\
refractive index (for $632.8 \mathrm{~nm})$ & $1.617-1.6195$ \\
transmission of light $[\mu \mathrm{m}]$ & $0.4-2.8$
\end{tabular}

The spectrum of transmission of the elaborated glasses was determined experimentally within the range $380 \div 1100 \mathrm{~nm}$ (Fig. 1). The optical transmission in the glass plates amounted to about $95 \%$, and their microhardness was $\approx 9 \mathrm{GPa}$. 
These properties permit to apply this kind of glass for the production of optical fibres.

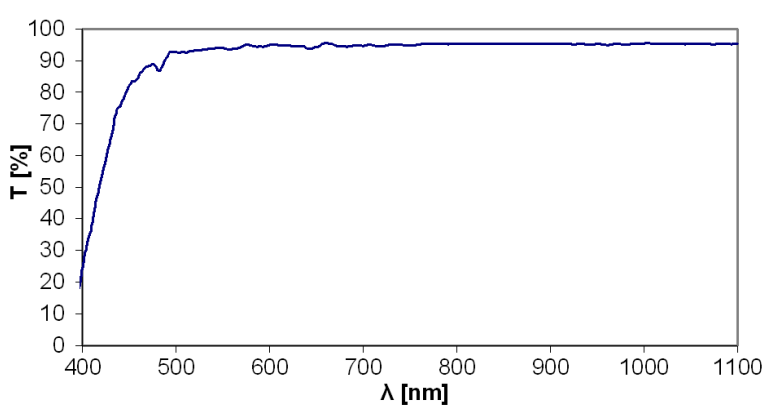

Fig. 1. Spectrum of transmission of the elaborated glass (for the $2 \mathrm{~mm}$ thickness of samples).

The presented kinds of glass possessed the high refractive index values (1.619), thanks to the modification of silica glasses by lead oxides. The obtained glasses were used first of all for the production of single mode optical fibres. These fibres must be modified by means of changing of a chemical composition of the glasses applied in the production of fibres [7-9]. In our glasses the refractive indices were modified by changing the percentage of the contribution of $\mathrm{PbO} / \mathrm{Al}_{2} \mathrm{O}_{3}$ (Fig. 2).

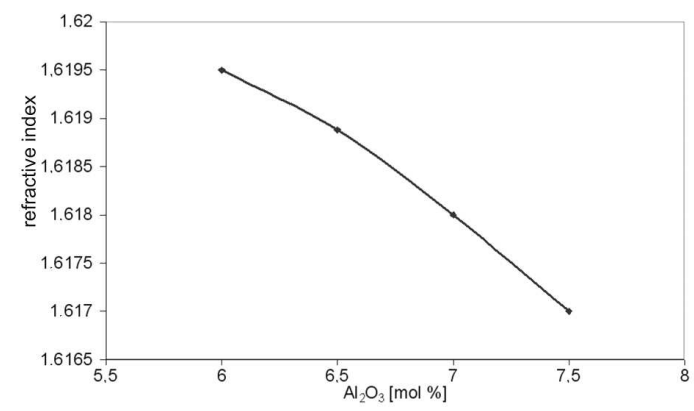

Fig. 2. Relation between the concentrations of $\mathrm{Al}_{2} \mathrm{O}_{3}$ in the obtained glasses and their refractive indices.

Besides adequate optical properties, optical fibres for sensor applications must be characterised by very small mechanical stresses. Mechanical stresses decide first of all about the random birefringent properties of the optical fibres. In order to restrict the random mechanical stresses in optical fibre the used glasses ought to be characterised by a high temperature of crystallisation $\left(T_{\mathrm{c}}\right)$. The temperature $T_{\mathrm{c}}$ ought to be much higher than the temperature of drawing of the optical fibre. The DSC characteristic of the glass used as the core is presented 
in Fig. 3. The transformation temperature $\left(T_{\mathrm{g}}\right)$ for this glass is equal to $449^{\circ} \mathrm{C}$ and a difference of specific heads, during the glass transformation is equal to $\Delta C_{p}=0.359 \mathrm{~J} \mathrm{~g}^{-1}{ }^{\circ} \mathrm{C}^{-1}$.

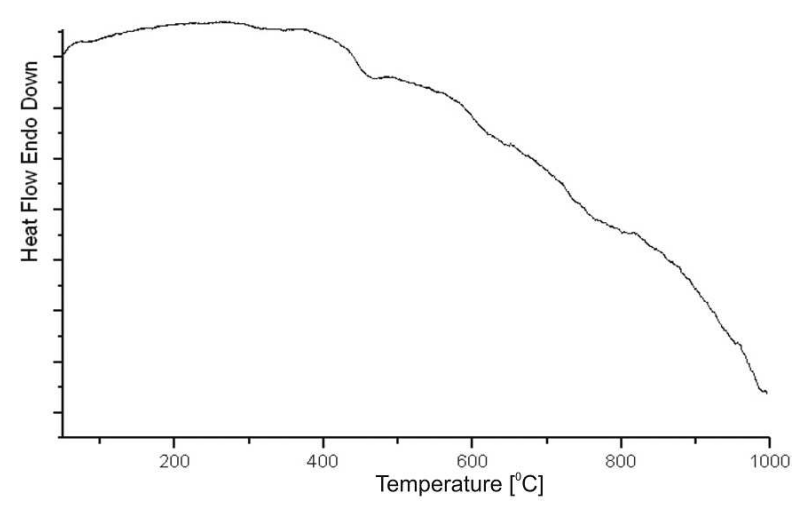

Fig. 3. The DSC characteristic of the core glass.

In the elaborated glasses, which were used in optical fibres, we did not observe a tendency to crystallisation during the processes of drawing of optical fibers. The value of the transformation temperature obtained experimentally corresponded to the value of $T_{\mathrm{g}}$ determined basing on the dilatometric analysis (Fig. 4).

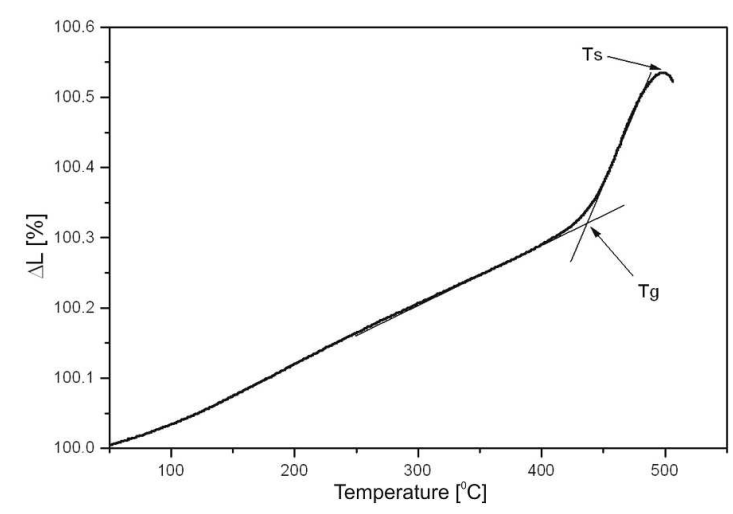

Fig. 4. Dilatometric characteristics of the core glass.

Table II presents the dilatation coefficients $A$ and characteristic temperatures ( $T_{\mathrm{g}}$ - temperature of transformation, $T_{\mathrm{s}}$ - melting temperature) of core and cladding glasses for the elaborated fibres. The dilatation coefficients $A$ of these gases are approximately equal to $85 \times 10^{-7} 1 / \mathrm{K}$. For this reason, the obtained kinds of glasses can provide optical fibres with very small stresses on the core-cladding boundary [10-12]. 
TABLE II

Thermal analysis of the core and cladding glasses for optical fibres.

\begin{tabular}{|c|c|c|}
\hline Parameter & Core glass & Cladding glass \\
\hline \multicolumn{3}{|l|}{ Dilatometer } \\
\hline dilatation coefficients (in $100-400^{\circ} \mathrm{C}$ range) $[10-71 / \mathrm{K}]$ & 89 & 85 \\
\hline temperature of transformation $T_{\mathrm{g}}\left[{ }^{\circ} \mathrm{C}\right]$ & 445 & 438 \\
\hline temperature of melting point $T_{\mathrm{s}}\left[{ }^{\circ} \mathrm{C}\right]$ & 535 & 500 \\
\hline \multicolumn{3}{|l|}{$\mathrm{DSC}$} \\
\hline temperature of transformation $T_{\mathrm{g}}\left[{ }^{\circ} \mathrm{C}\right]$ & 449 & 445 \\
\hline
\end{tabular}

The glasses described above were used to obtain single mode fibres (at $633 \mathrm{~nm}$ wavelength) with a refractive index of the core $n>1.6$. In order to satisfy the single mode condition for these fibres by the relatively high core diameter $(12 \mathrm{~mm})$ a very accurate control of the difference between their core and cladding refractive indices is required, which ought to be $\Delta n=0.0005$. For the production of the single mode fibres the crucible method was applied. During the fiber drawing processes the viscosity of the glasses was $10^{4}-10^{5} \mathrm{dPa}$, which corresponds to the temperature $\approx 910^{\circ} \mathrm{C}[4,12]$. Figure 5 presents the cross-section of a single mode fibre. The experimental value of the attenuation coefficient of light $\alpha$ for these elaborated fibers (determined by means of the cut method) for the waveguide $\lambda=633 \mathrm{~nm}$ is equal to $\alpha=0.1 \mathrm{~dB} / \mathrm{m}$.

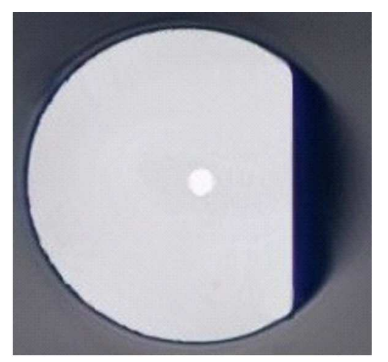

Fig. 5. Cross-section of the elaborated optical fibre: $\Delta n=0.0005$, external diameter $\approx 150 \mu \mathrm{m}$, diameter of core $\approx 12 \mu \mathrm{m}$, numerical aperture $\mathrm{NA}=0.04$.

Mechanical strength of the optical fibres was defined by determining Weibull's distribution for a series of 50 fibre raptures (Fig. 6). During the raptures the mechanical stress in the fibres was $\approx 121 \mathrm{~N} / \mathrm{mm}^{2}$ at the value $3.2 \mathrm{~N}$ of the tensing force. The minimum bend radius, at which the fibers did not fracture, was $\approx 3 \mathrm{~cm}$. 


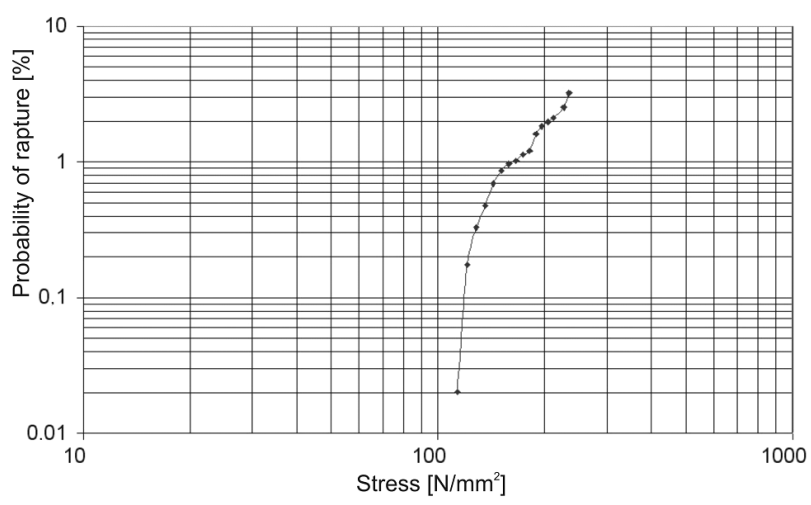

Fig. 6. Weibull's distribution of fibre raptures.

\section{Conclusions}

The presented results of the new elaborated optical fibres seem to be promising. The fibres possess higher values of refractive indices and relatively good mechanical properties. The optical fibres are going to apply in optical sensors of magnetic field and electric current. Preliminary investigations were still carried out and will be published.

\section{Acknowledgments}

The work was sponsored by the State Committee for Scientific Research within the grant N N515 409534.

\section{References}

[1] B.D. Gupta, Fiber Optic Sensor, Principles and Applications, NIPA, Delhi 2006.

[2] D. Dorosz, J. Swiderski, A. Zajac, M. Reben, in: Proc. XXI Int. Congress on Glass, Strasbourg 200\%, p. 149.

[3] R. Romaniuk, in: Optical Fiber Metrology, XVI Domestic Conf. on Optoelectronics, Zakopane (Poland) 2001, p. 8 (in Polish).

[4] J. Dorosz, Polski Biuletyn Ceramiczny, Ceramika 86, 115 (2005) (in Polish).

[5] Lee Byoungho, Opt. Fiber Techn. 9, 57 (2003).

[6] A.H. Rose, Am. Ceram. Soc. Bull. 79, 40 (2000).

[7] C.Z. Tan, J. Arndt, J. Phys. Chem. Solids 60, 1689 (1999).

[8] K. Barczak, T. Pustelny, A. Szpakowski, M. Blahut, J. Phys. IV (France) 129, 85 (2005).

[9] E. Nazarowa, A. Tcheryatian, Mol. Quant. Acoust. 28, 259 (2007).

[10] K. Barczak, T. Pustelny, D. Dorosz, J. Dorosz, Europ. Phys. J. Special Topics 154, 11 (2008).

[11] A. Skumiel, M. Labowski, Mol. Quant. Acoust. 27, 233 (2006).

[12] K. Kurosawa, in: OFS-11, Japan 1996, p. 134. 